\title{
Dexamethasone for Morbidity After Subdural Electrode Insertion - A Randomized Controlled Trial
}

\author{
Ramesh L. Sahjpaul, Jeff Mahon, Samuel Wiebe
}

\begin{abstract}
Background: Invasive monitoring with subdural electrodes (SDE) for investigation of medically intractable epilepsy may be associated with undesirable immediate postoperative morbidity such as headache, nausea, vomiting, fever, and meningism. We undertook to evaluate the potential beneficial role of perioperative dexamethasone in reducing these symptoms. Methods: In a double-blind placebo controlled clinical trial 30 patients undergoing SDE insertion were randomized to receive either placebo or a course of dexamethasone beginning one hour prior to surgery and tapering to discontinue over 72 hours postoperatively. Pain, pain relief, nausea, nausea relief, temperature, and meningism were assessed regularly in the postoperative period, and analgesic, antipyretic, and antiemetic drug requirements were tabulated. Results: One patient was withdrawn from the dexamethasone group due to lack of data. With regards to postoperative pain, the direction of benefit favoured dexamethasone but a significant treatment by time interaction prevented further analysis of treatment effect. The dexamethasone group did have significantly lower temperatures and higher nausea relief scores. There was no statistically significant difference between the groups with regards to pain relief, nausea, and meningism scores. The beneficial effects of dexamethasone were delayed in onset, of limited duration, and not uniform over the observation period. Conclusion: Dexamethasone appears to have a role in reducing immediate morbidity following SDE insertion but its effect is not uniform in the postoperative period; it appears to be delayed in onset, and of limited duration. Further study is necessary to determine the ideal dosing schedule.
\end{abstract}

RÉSUMÉ: Effet de la dexaméthasone sur la morbidité suite à l'insertion d'électrodes sous-durales - une étude randomisée à double insu contrôlée par placebo. Introduction: La surveillance effractive au moyen d'électrodes sous-durales (ÉSD) dans l'investigation de l'épilepsie réfractaire au traitement médical peut être associée à une morbidité postopératoire immédiate dont la céphalée, les nausées, les vomissements, l'hyperthermie et le méningisme. Nous avons évalué si la déxaméthasone administrée pendant la période périopératoire pouvait réduire ces symptômes. Méthodes: Trente patients qui devaient subir l'insertion d'ÉSD ont été répartis de façon aléatoire au traitement à la déxaméthasone une heure avant la chirurgie et à dose décroissante dans les 72 heures après la chirurgie ou à recevoir un placebo. La douleur, le soulagement de la douleur, les nausées, le soulagement des nausées, la température et le méningisme ont été évalués régulièrement en période postopératoire et les besoins en médicaments analgésiques, antipyrétiques et antiémétiques ont été notés. Résultats: Un patient a été exclu du groupe recevant la dexaméthasone à cause de données manquantes. En ce qui concerne la douleur postopératoire, la dexaméthasone semblait être bénéfique, bien que les données n'aient pu être analysées de façon plus poussée à cause d'une interaction entre le traitement et le temps. Le groupe recevant de la dexaméthasone avait une température significativement plus basse ainsi qu'un meilleur score de soulagement des nausées. La différence entre les groupes quant au soulagement de la douleur, aux nausées et au méningisme n'atteignait pas le seuil de la significativité. Les effets bénéfiques de la dexaméthasone avaient un début tardif, une durée limitée et étaient variables pendant la période d'observation. Conclusion: La dexaméthasone semble jouer un rôle dans la réduction immédiate de la morbidité après l'insertion d'ÉSD mais son effet est variable pendant la période postopératoire: le début est retardé et l'effet est d'une durée limitée. D'autres études sont nécessaires pour déterminer quel est le schéma posologique idéal.

Can. J. Neurol. Sci. 2003; 30:340-348

Outcome from epilepsy surgery is directly related to the identification of and extent of resection of epileptogenic brain areas. Compared to other monitoring techniques invasive ictal monitoring provides the most accurate data for selecting surgical candidates. ${ }^{1}$ Since the inception of the Epilepsy Unit at London Health Sciences Center (LHSC) in 1977 invasive monitoring has been performed almost exclusively with subdural electrodes (SDE). Due to its national and international referral base the Unit attracts patients with complex epilepsy disorders often requiring extensive SDE insertion for investigation. Past experience suggested that SDE insertion is associated with significant postoperative pain (headache) disproportionate to the degree of scalp incisions and bone removal (Wiebe et al, 1996 unpublished data). The occurrence of headache along with fever, neck stiffness, nausea and vomiting, and the beneficial response to

From the Divisions of Neurosurgery (RLS) and Neurology (SW), Department of Clinical Neurological Sciences, and Department of Medicine (JM), University of Western Ontario, London, Ontario, Canada.

RECEIVED OCTOBER 9, 2002. ACCEPTED IN FINAL FORM APRIL 16, 2003 Reprint requests to: Ramesh Sahjpaul, Division of Neurosurgery, University of British Columbia, D6 Heather Pavilion, 2733 Heather Street, Vancouver BC Canada 
treatment with dexamethasone in many cases, suggested meningeal irritation/inflammation as a possible etiology, which is consistent with observations regarding the use of dexamethasone in other neurosurgical ${ }^{2-7}$ and non-neurosurgical ${ }^{8}$ operations. However, there have been no studies addressing the efficacy and risk of dexamethasone in the SDE patient population. We conducted a randomized double blind placebocontrolled trial to determine the effect of perioperativelyadministered dexamethasone on patient morbidity following SDE insertion. Primary and secondary outcome criteria were chosen to critically evaluate the potential benefits of dexamethasone.

\section{Clinical Materials AND METHODS}

\section{General design and study setting}

The study was a prospective, randomized, double blind, placebo-controlled, single center clinical trial conducted at the
LHSC Epilepsy Unit, a tertiary care facility that provides specialized care to a local, national, and international referral base of patients with medically intractable epilepsy. Once eligibility for the study was determined and consent obtained, patients were randomized to receive either dexamethasone or placebo perioperatively (Figure 1).

\section{Patient population and sample size}

The study protocol received ethical and scientific approval after formal internal review. Over a period of 18 consecutive months, patients undergoing SDE placement for the investigation of medically intractable epilepsy were recruited. Patients were assessed for study eligibility by the senior author and the study nurse as soon as the decision to proceed with SDE insertion was made by the attending neurologist. All patients underwent a complete history and physical assessment on admission, along with standard investigations prior to surgery (serum electrolytes, glucose, coagulation profile, blood urea

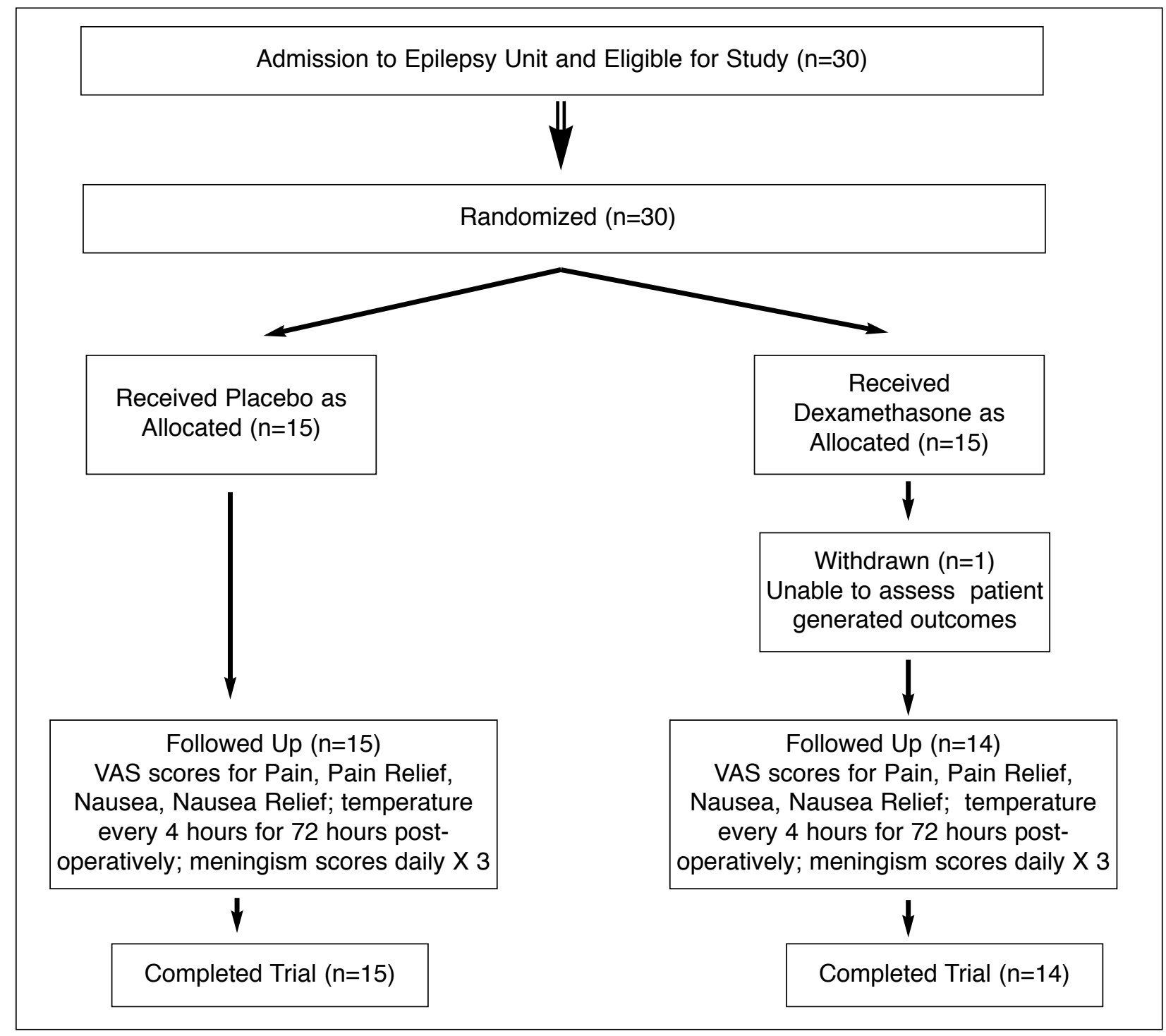

Figure 1: Study flow diagram. 
nitrogen, creatinine, complete blood count, electrocardiogram, chest X-ray (if $>40$ years of age), and magnetic resonance imaging (MRI) of the brain. All patients provided informed consent prior to entering the study.

\section{Inclusion criteria}

1) Medially intractable epilepsy requiring SDE insertion as part of the medical workup.

2) Age greater than 16 years.

3) Provision of informed consent.

\section{Exclusion criteria}

1) Patient refusal to enter study.

2) Inability to communicate with nurses/investigators due to language impairment, degree of mental retardation, or other psychiatric disorders.

3) Inability to use the Visual Analogue Scale (VAS).

4) History of chronic headaches or other chronic pain syndrome.

5) Medical condition precluding use of corticosteroids.

\section{Sample size calculation}

Sample size was calculated using GraphPad InStat ${ }^{\mathrm{TM}}$ GraphPad Software, V2.O2+ (D Cechetto, John P Robarts Research Inst. 931122S). The size of the treatment effect that represents a boundary between what is clinically important and what is considered trivial, i.e. the minimal clinically important difference (MCID), is difficult to determine and is often arbitrary, but is a critical methodological step in the design of a study. In clinical studies using the VAS, an MCID ranging from $1 \mathrm{~cm}$ to $3 \mathrm{~cm}$ has been suggested (Moulin, personal communication, 2001). The MCID is inversely related to the sample size required to show the presence of treatment effect. For this study, and in the absence of clear guidelines for VAS MCID, a value of $3 \mathrm{~cm}$ was chosen a priori following the example of Wiebe et al (unpublished data, 1996) who successfully utilized an identical VAS scale in an identical patient population in the Epilepsy Unit at LHSC in 1996. Using alpha $\alpha=0.05$ two tailed, beta $\beta=0.05$ (95\% power), and an estimated $10 \%$ dropout rate a sample size of $n=12.8$ per group was calculated; a conservative estimate of 15 patients per group was thus chosen.

The sample size calculation in this study was conservative in that the estimated variance $\mathrm{s}^{2}=3.57$ observed in the pilot study by Wiebe et al (unpublished data, 1996) was rounded up to 4, and power was chosen as $95 \%$ - much higher than the conventional $80 \%$ figure. If, in fact, we had used $\mathrm{s}^{2}=3.57$, and a conventional $\beta=0.20$ ( $80 \%$ power), the sample size of this study was sufficient to detect a difference as small as $2.5 \mathrm{~cm}$ in the primary outcome (pain VAS score).

\section{Primary hypothesis}

The primary hypothesis was that perioperative dexamethasone decreases postoperative pain in patients undergoing SDE insertion.

\section{Secondary hypotheses}

We also addressed several prespecified secondary hypotheses: Compared to placebo, dexamethasone as administered above:

1) Improves pain relief.

2) Reduces nausea and improves nausea relief.
3) Reduces postoperative fever and meningism.

4) Reduces the requirement for analgesic, antipyretic, and antiemetic medications.

\section{Randomization}

On the morning of surgery, patients were randomized to receive dexamethasone or placebo perioperatively. Randomization was performed by the LHSC Pharmacy Department in blocks of 4 using a sealed envelope technique. After enrollment into the study patients were prepared for surgery. All members of the treatment team and the outcome assessor (study nurse) were blinded to the treatment group. The randomization code was held in the Pharmacy Department and could, in the event of an emergency thought possibly to be related to the test drug, be immediately opened.

\section{Pre- and intra-operative management}

Pre-operative management was consistent with routine practice at LHSC. Patients were kept fasting as of midnight prior to surgery and were given their usual medications, other than analgesics, on the morning of surgery. An IV with Ringer's lactate solution was started and pre-operative antibiotic prophylaxis was administered (cefazolin $1 \mathrm{gm} \mathrm{IV}$ or vancomycin $1 \mathrm{gm} \mathrm{IV} \mathrm{if} \mathrm{allergic} \mathrm{to} \mathrm{cefazolin).} \mathrm{One} \mathrm{hour} \mathrm{prior} \mathrm{to} \mathrm{surgery,} \mathrm{the}$ pre-operative dose of dexamethasone $10 \mathrm{mg}$ IV or placebo was infused. Intra-operative patient monitoring consisted of electrocardiography, pulse oximetry, capnography, a noninvasive blood pressure device and an esophageal temperature probe. A warming blanket was used to maintain normothermia throughout the procedure. All patients received the same anesthetic protocol. Following induction of general anesthesia with propofol $(2 \mathrm{mg} / \mathrm{kg})$ and fentanyl $(2-3 \mu \mathrm{g} / \mathrm{kg})$, patients were intubated using vecuronium and ventilated to normocapnia (end tidal $\mathrm{CO}_{2}=40$ $\mathrm{mmHg}$ ). Anesthesia was maintained with isoflurane (0.5-1.5 vol\%) in nitrous oxide and oxygen $\left(\mathrm{FiO}_{2}=0.35\right)$, supplemented with additional doses of fentanyl to a maximum of $5 \mu \mathrm{g} / \mathrm{kg}$. Fentanyl was chosen because of its short half-life $\left(t^{1} / 2=10-30\right.$ minutes), which ensured that intraoperatively administered narcotic analgesic was not a factor in postoperative pain levels.

\section{Surgical technique of subdural electrode placement}

The surgical technique utilized by the three surgeons involved in the study was identical. After shaving the head, the patient is positioned supine with the head flexed and supported on a beanbag. Intraoperative fluoroscopy that allows both anteroposterior and lateral views is essential. Electrodes are inserted through posterior auricular (for temporal, parietal, and occipital coverage), supraorbital (for orbitofrontal coverage) or midline (for interhemispheric and convexity coverage) burr holes (Figure 2).

\section{Postoperative management, dexamethasone dosing and outcome measurement}

Postoperatively, all patients underwent stereoscopic skull radiographs to determine electrode placement (routine practice). Requirement for analgesia (morphine or fentanyl) and antiemetic (metoclopramide or ondansetron) in the recovery room was documented. Patients were then transferred to the Epilepsy Unit. Postoperative analgesia was administered using a patient controlled analgesia (PCA) pump. The first patient enrolled in 


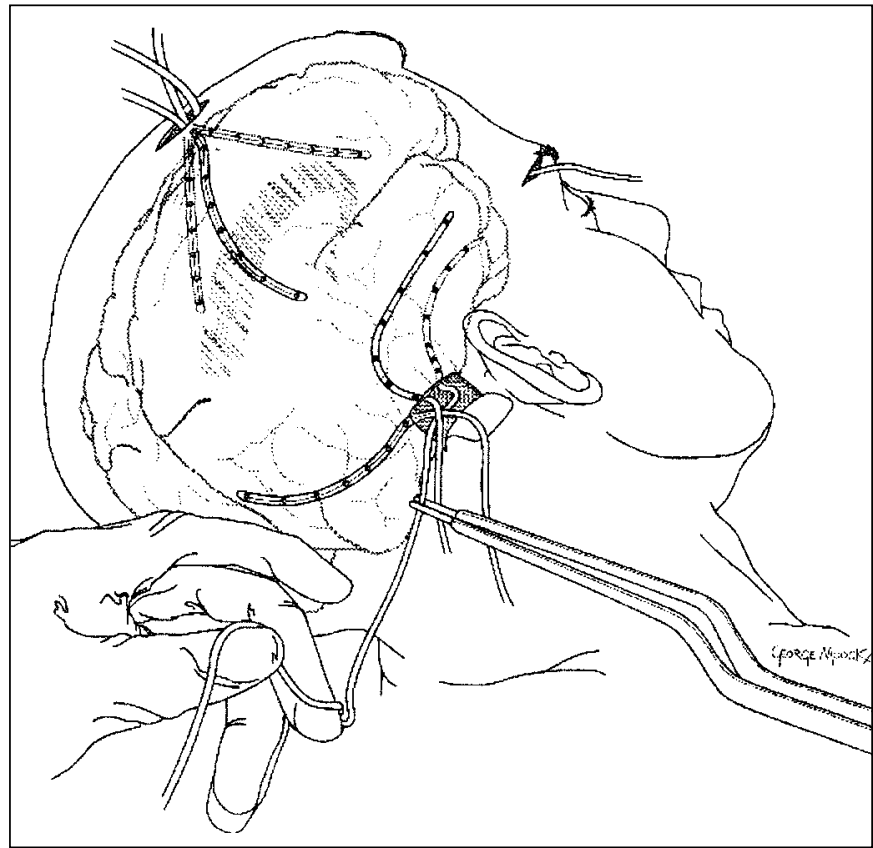

Figure 2: Surgical technique of subdural electrode placement at LHSC showing commonly used burr hole positions (posterior auricular for temporal, parietal, and occipital coverage, midline for interhemispheric or convexity coverage, and supraorbital for orbitofrontal coverage).

the study received PCA fentanyl but all subsequent patients received PCA morphine as it was considerably cheaper. Dexamethasone was administered according to the following schedule: $4 \mathrm{mg}$ IV q6h X 4 doses, $2 \mathrm{mg}$ IV q6h X 4 doses, $2 \mathrm{mg}$ IV $\mathrm{q} 12 \mathrm{~h} \mathrm{X} 2$ doses. This allowed a rapid taper over 72 hours. All patients received ranitidine $50 \mathrm{mg}$ IV q8h or $150 \mathrm{mg}$ po bid while they received dexamethasone or placebo. Patient-specific worksheets were used to record and tabulate physiologic measurements as well as medications consumed for 72 hours postoperatively. The study nurse assessed the degree of meningism and ensured all data was collated. A core group of experienced Epilepsy Unit nurses cared for the patients in the postoperative period for the duration of the study. The following parameters were recorded:

1) VAS scores (0-10) for pain, pain relief, nausea, and nausea relief every 4 hours.

The sliding scale VAS device was held by the nurse and the patient moved the slide indicator between "no pain" (0) and "worst pain ever" (10). We allowed patients to see their previous VAS scores as Guyatt et $\mathrm{al}^{9}$ have shown reduced variance (increased precision) in outcome measurements by allowing patients to see their previous ratings. The VAS was utilized because of its ease and brevity of administration, minimal obtrusiveness, and conceptual simplicity, and because it has been shown to be valid and reliable in the assessment of acute pain in humans. ${ }^{10,11}$ Relief scores for pain and nausea were also directly measured as recommended by several investigators. ${ }^{11-14}$

2) Temperature every four hours.

3) Meningism.
This was assessed by the study nurse once every morning for three days in all patients by actively flexing the patient's neck and grading the degree of resistance offered: none (0), mild (1), moderate (2), or severe (3).

4) Medications received (antipyretic, analgesic, antiemetic) beginning in the immediate postoperative period.

For statistical analysis, all analgesics were expressed as morphine-equivalents, and antiemetics as metoclopramide equivalents, using the following ratios: morphine:fentanyl 10:1; morphine:codeine 1:6, ondansetron:metoclopramide: dimenhydrinate $0.8: 1: 5$

5) Complications/adverse effects.

\section{Postoperative care}

For the first 24-48 hrs patients were nursed with the head of bed elevated $\left(45^{\circ}\right)$ to reduce cerebrospinal fluid (CSF) leakage. The dressings were changed as necessary, usually two days after surgery, and then every three to four days as required. A sterile surgical scrub solution was used at the site of electrode entrance and along approximately $20 \mathrm{~cm}$ of the electrode itself. The incision sutures were removed at five to seven days. Postoperative antibiotics were not administered. Electrodes were removed on the ward when a sufficient number of representative seizures had been recorded (typically a minimum of three).

\section{Statistical analysis}

\section{Primary and secondary analyses}

Analyses of the outcome variables used the intention-to-treat principle. All statistical analyses were performed using SPSS ${ }^{\circledR}$ version (SPSS, Inc., Chicago, IL). Pain, pain relief, nausea, nausea relief, temperature, and meningism outcome data were analyzed using repeated measures analysis of variance (ANOVA). The Greenhouse-Geisser coefficient was used for testing the treatment by time interaction, followed by testing for treatment effect if there was no significant interaction.

\section{Missing data}

Missing data were dealt with using a simple and conservative imputation strategy described by Pledger ${ }^{15}$ for the few missing data points in 29 patients with mostly complete data: the previous value was carried forward or the median for the group was used if the missing value was the first in the series. In the case of one patient in the dexamethasone group (henceforth, Withdrawn Subject or W.S.) the amount of missing data necessitated withdrawal from the final analysis. To determine if withdrawal affected the final analysis the latter was done both with and without W.S.

\section{Exploratory analyses}

A linear regression analysis $\left(\mathrm{SPSS}^{\circledR}\right)$ was performed using mean pain VAS score as the dependent variable and gender, age, number and location (subtemporal or not) of SDE inserted as the independent variables.

\section{RESUlTS}

Of 42 patients scheduled to undergo SDE insertion between October 1997 and May 1999, written informed consent was obtained from all 30 patients who met the inclusion criteria for the study. The randomization procedure resulted in 15 patients 
Table 1: Baseline Characteristics of Study Participants

\begin{tabular}{lcc}
\hline & $\begin{array}{c}\text { Group 1 } \\
\text { (Control) }\end{array}$ & $\begin{array}{c}\text { Group 2 } \\
\text { (Dexamethasone) }\end{array}$ \\
& $\begin{array}{c}\text { n=15 } \\
\text { (mean } \pm \text { SD) }\end{array}$ & $\begin{array}{c}\text { n=14 } \\
\text { (mean } \pm \text { SD) }\end{array}$ \\
Age (years) & $34.4 \pm 10$ & $39.6 \pm 10.8$ \\
Sex (Male/Female) & $7 / 8$ & $6 / 8$ \\
Weight (kg) & $72.2 \pm 15$ & $82.0 \pm 16.8$ \\
Height (cm) & $168 \pm 8.8$ & $166.8 \pm 7.8$ \\
Number of antiepileptic drugs & $1.9 \pm 0.89$ & $2.0 \pm 0.54$ \\
Duration of Epilepsy (years) & $17.8 \pm 8.8$ & $20.0 \pm 8.1$ \\
Number of electrodes & $8.1 \pm 3.3$ & $7.6 \pm 3.0$ \\
Average length of stay in EU (days) & $8.13 \pm 3.29$ & $7.9 \pm 3.06$ \\
Brain Pathology Responsible for Epilepsy & \\
$\quad$ Traumatic Scar & 2 & 1 \\
$\quad$ Mesial temporal sclerosis & 5 & 0 \\
Tumor & 1 & 3 \\
Neuronal migration disorder & 3 & 2 \\
Resective surgery not offered & 4 & \\
& &
\end{tabular}

assigned to the control and 15 to the dexamethasone groups. No patients were lost to follow-up. Baseline characteristics between the two groups were comparable (Table 1) (Patient W.S. (see below) is not included). Duration of electrode implantation was not significantly different between the two groups (Table 1).

\section{Missing values (Patient W.S. - Dexamethasone Group)}

This patient met all inclusion criteria for the study, received the intervention, co-operated with objective outcome assessment (temperature and meningism) but was not able to complete the VAS scores because of somnolence and irritability. This resulted in an excessive amount of missing data (11 of a possible 19 data points $(57.9 \%)$ for pain VAS and $32 / 76$ data points $(57.9 \%)$ for all VAS scores), and the patient was withdrawn from the analysis. Data analysis performed with and without W.S. failed to demonstrate any effect of this withdrawal.

\section{Primary and secondary outcome measures}

The baseline VAS scores for all study patients were 0 for pain and nausea (i.e. no pain or nausea) and 10 for pain relief and nausea relief (i.e. complete relief). All patients had baseline meningism scores of 0 (no meningism) and were afebrile.

Results from the repeated measures ANOVA are summarized in Table 2. For pain scores, a significant interaction between treatment effect and time was detected $(\mathrm{p}=0.04)$. Proceeding with a test for treatment effect is misleading in the presence of significant interaction, but considerable information and clinical relevance can be gleaned from an analysis of the graphical plots comparing the control and dexamethasone marginal means over time (Figure 3a): (1) both groups were uncomfortable during the first day following surgery with pain scores as high as 5/10, (2) the two groups had similar pain scores during the first and third days after surgery but exhibited markedly different scores during the second day after surgery when the dexamethasone group had a lower marginal mean pain score, and (3) the control and dexamethasone groups both improved over time such that by the end of the third day pain scores were approximately $20 \%$ of the initial value.

No treatment-by-time interaction was detected for pain relief, nausea, nausea relief, temperature, and meningism scores. Subsequent test of overall treatment effect showed significantly higher nausea relief scores and lower temperatures in the dexamethasone-treated group ( $\mathrm{p}=0.03$ and 0.007 , respectively) (Table 2). However, the groups were not significantly different with regard to pain relief, nausea, and meningism scores $(p>0.05)$. Visual inspection of the graphical plots of estimated marginal means for pain relief (Figure 3b), nausea (Figure 3c), nausea relief (Figure 3d), temperature (Figure $3 \mathrm{e}$ ), and meningism (Figure $3 \mathrm{f}$ ) shows patterns similar to those observed in the aforementioned pain plot (Figure 3a).

The results of the ANOVA for drug consumption are shown in Table 3. The direction of the association between the amount of analgesic and antipyretic used and allocation to placebo or

\section{Table 2: Results of Repeated Measures ANOVA}

\begin{tabular}{|c|c|c|c|c|}
\hline \multirow[t]{2}{*}{ Variable } & \multicolumn{2}{|c|}{ Estimated Marginal Means } & \multirow{2}{*}{$\begin{array}{l}\text { Tests of interaction between treat- } \\
\text { ment effects over time (p value) } \\
\text { (Greenhouse-Geiser coefficient) }\end{array}$} & \multirow{2}{*}{$\begin{array}{l}\text { Test of treatment } \\
\text { effects ( } p \text { value) }\end{array}$} \\
\hline & $\begin{array}{l}\text { Group } 1 \\
\text { (Control) }\end{array}$ & $\begin{array}{l}\text { Group } 2 \\
\text { (Dexamethasone) }\end{array}$ & & \\
\hline Pain (Relief VAS score) & 6.510 & 7.219 & 0.08 & 0.31 \\
\hline Nausea (VAS score) & 2.041 & 1.223 & 0.18 & 0.20 \\
\hline Nausea Relief (VAS score) & 6.627 & 8.556 & 0.57 & $0.03 * *$ \\
\hline ( ${ }^{\circ}$ Celsius) & 37.144 & 36.843 & 0.22 & $0.007 * *$ \\
\hline Meningism & & & & \\
\hline (Grade $0-3$ ) & 0.467 & 0.095 & 0.10 & 0.10 \\
\hline
\end{tabular}

\footnotetext{
*significant treatment by time interaction precludes further testing of treatment effect
}

**significant treatment effect 

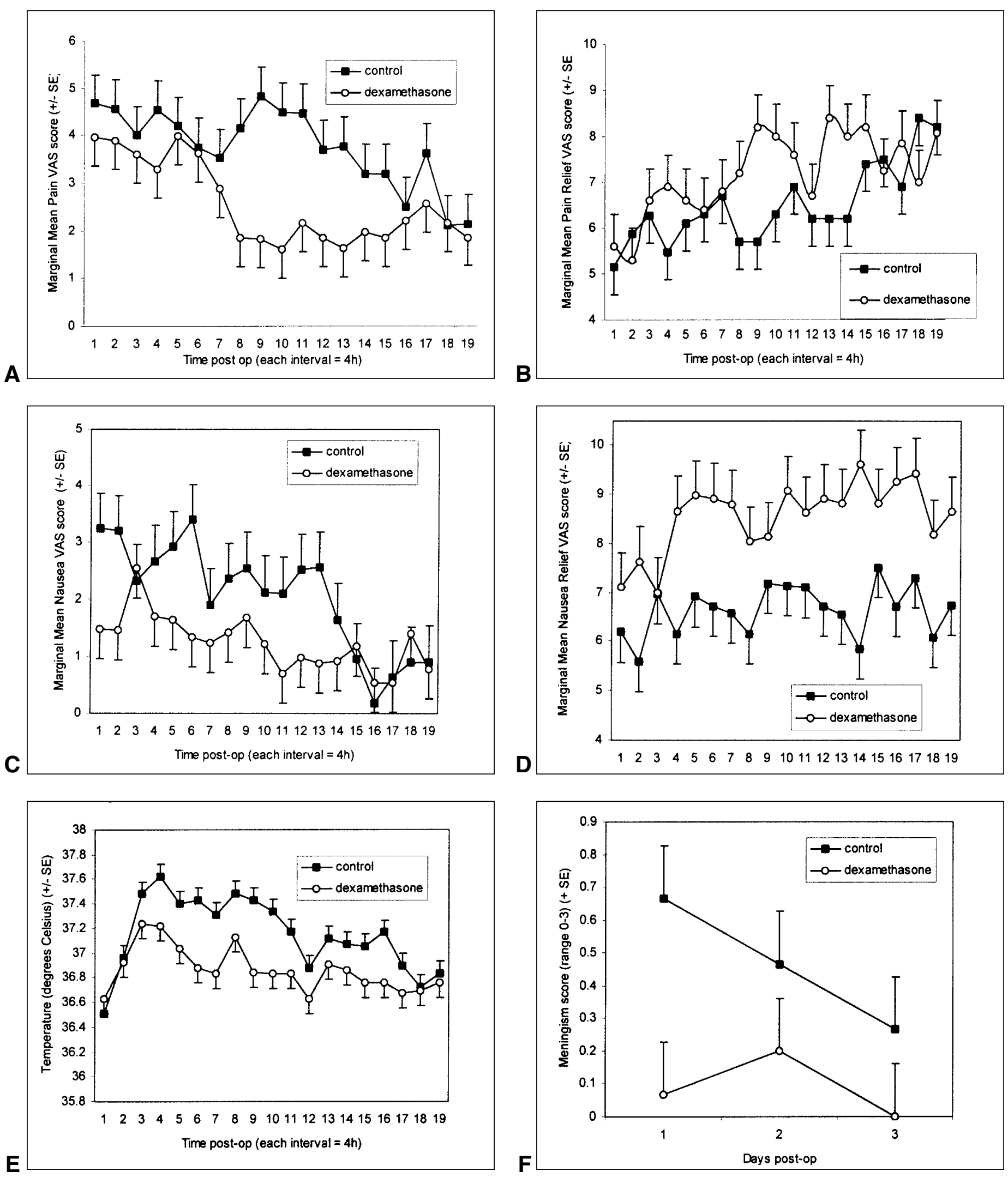

Figures 3a-f: Graphs showing estimated marginal means as a function of time post op for (a) Pain, (b) Pain Relief, (c) Nausea, and (d) Nausea Relief VAS scores (range 0-10), for (e) Temperature $\left({ }^{\circ}\right.$ Celsius $)$, and for $(f)$ Meningism scores $(0=$ none, $1=$ mild, $2=$ moderate, $3=$ severe $)$. 


\section{Table 3: Results of ANOVA for Drug Use}

\begin{tabular}{lccc}
\hline $\begin{array}{l}\text { Medication (expressed as } \\
\text { equivalents of drugs }\end{array}$ & $\begin{array}{c}\text { Group I } \\
\text { (placebo) } \\
\text { listed below) }\end{array}$ & $\begin{array}{c}\text { Group II } \\
\text { (dexamethasone) }\end{array}$ & p value \\
& mean \pm SD $(\mathrm{mg})$ & mean \pm SD $(\mathrm{mg})$ & \\
& &
\end{tabular}

\section{Analgesic}

$\begin{array}{llll}\text { (Morphine equivalent) } & 100.0 \pm 48.5 & 70.9 \pm 47.8 & 0.115\end{array}$

Antiemetic

$100.0 \pm 48.5 \quad 70.9 \pm 47.8 \quad 0.115$

$\begin{array}{lll}\text { (Metoclopramide equivalent) } & 26.7 \pm 28.8 \quad 30.0 \pm 40.6\end{array}$

Antipyretic

(Acetaminophen equivalent) $823.3 \pm 1862.4 \quad 185.7 \pm 472$

dexamethasone was congruent with the changes seen in many of the outcome measures shown in Table 2 with the dexamethasone group requiring less analgesic $(70.9 \mathrm{mg} \pm 47.8 \mathrm{vs}$. $100.0 \mathrm{mg} \pm$ $48.5)$ and less antipyretic medication $(185.7 \mathrm{mg} \pm 472 \mathrm{vs} .838 \mathrm{mg}$ \pm 1862) compared to the placebo group, but statistical significance was not reached $(\mathrm{p}=0.115$ and 0.225 , respectively). The dexamethasone group required slightly more antiemetic medication than the control group, but this difference was also not significant $(\mathrm{p}=0.80)$.

\section{Adverse outcomes}

There were no adverse outcomes noted during the course of the study or hospitalization.

\section{Exploratory analyses}

Results of the linear regression analysis using mean pain score over the three-day observation period as the dependent variable and gender, age, and location and number of SDE as the independent variables revealed that only age had a significant unstandardized regression coefficient of -0.098 ( $\mathrm{p}=0.004)$, indicating that younger patients experienced more pain in the postoperative period.

\section{DiscuSSION}

\section{Morbidity of subdural electrode insertion and rationale for dexamethasone use}

While the effectiveness of surgery for medically intractable epilepsy has now been unequivocally established, ${ }^{16}$ its success is directly related to the identification of epileptogenic brain areas. Despite advances in both structural and functional neuroimaging, invasive monitoring with subdural or depth electrodes continues to be an important technique in determining surgical candidacy and for surgical planning. Invasive monitoring rates in adult epilepsy centers ranges from 25-50\%. ${ }^{17}$ Morbidity associated with SDE insertion can be considered to be immediate (hours to days) or delayed (days to weeks). Delayed morbidity is largely limited to a 1-2\% risk of infection. ${ }^{18-24}$ Experience at this center has been similar. Although there is no mention of immediate morbidity (pain (headache), fever, nausea, vomiting, and meningism) in the literature - perhaps because it is not considered to be clinically important - our own experience suggested that virtually all patients experienced this symptom complex for several days following surgery. In addition, the headache and meningism seemed to be resistant to the usual postoperative analgesics but responsive to dexamethasone. Such morbidity has several potentially undesirable consequences beyond the obvious negative effects to the individual patient. Uncomfortable patients are less co-operative, require more intensive nursing care, and tend to be restless which results in degradation of the quality of the EEG recording and possibly missed seizures; this may lengthen monitoring times, thereby increasing the cost of investigation and patient risk. The cause of this immediate morbidity is likely multifactorial. The nausea and vomiting may be due to the effects of general anesthesia alone or may, in fact, along with the other signs and symptoms, be due to aseptic meningitis. This entity was first described in relation to epilepsy surgery in 1954 by Penfield, ${ }^{25}$ who believed that it was due to blood in the subarachnoid space. Other investigators have also described this phenomenon, ${ }^{2,3,26}$ and resolution of clinical symptoms has been shown to correlate directly with a decrease in CSF bilirubin levels. ${ }^{27}$ Subarachnoid blood induces an acute meningeal reaction characterized by the presence of an inflammatory infiltrate. ${ }^{28-31}$ It is conceivable that foreign bodies, such as SDE, may incite a similar, if not more severe, inflammatory response, and the benefit of potent antiinflammatory agents such as dexamethasone has been advocated in such circumstances., ${ }^{2,27}$ Systemic administration of steroids has been associated with a decreased incidence of postoperative fever and a decreased CSF cellular inflammatory response in patients undergoing craniotomy for tumor. ${ }^{27}$ The benefit of perioperative dexamethasone in reducing morbidity following spinal procedures has also been well-documented. ${ }^{4-7}$

The efficacy of perioperative dexamethasone for other surgical procedures has also been reported, predominantly in the anesthesia literature, and especially with regards to its ability to reduce postoperative nausea and vomiting. A single prophylactic dose of dexamethasone has been shown to be antiemetic compared with placebo and without evidence of any clinically relevant toxicity in otherwise healthy patients..$^{8,32,33}$ The mechanism by which dexamethasone exerts its antiemetic effect is not known with certainty but glucocorticosteroid receptors have been found in brainstem nuclei known to have significant neuronal activity in the regulation of the nausea and vomiting reflex. ${ }^{31}$

Although prolonged use of dexamethasone is associated with well-documented side effects, many of which are potentially life threatening, ${ }^{31}$ a short course of treatment such as that used in this study, has been shown to be safe..$^{4-7,32-37}$

\section{Dexamethasone dosing and method of administration}

Dexamethasone dosing and methods of perioperative administration have varied considerably. ${ }^{31}$ The dose used in the anesthesia literature for prevention of postoperative nausea and vomiting has typically been $10 \mathrm{mg} I \mathrm{~V}$ just prior to surgery or at the time of induction of anesthesia. . $^{8,32,33,37}$ In the neurosurgical studies, the dose has been more substantial and for a longer duration. Wyler ${ }^{2}$ used $10 \mathrm{mg}$ IV approximately one hour prior to craniotomy and continued this dose for 48 hours before stopping without tapering. In spinal procedures, Glasser et $\mathrm{al}^{6}$ administered methylprednisolone $250 \mathrm{mg}$ IV at the start of surgery, and King ${ }^{5}$ used dexamethasone $10 \mathrm{mg}$ IV followed by 
$4 \mathrm{mg}$ every six hours for three days following surgery. In our experience (unpublished data), immediate morbidity persisted for a few days following SDE insertion. Hence, for the purpose of this study, we elected to follow conventional practice among the neurosurgeons at LHSC, which was very similar to the dosing regimen described by King, ${ }^{5}$ with the exception that local practice has been to taper the drug rapidly over two to three days postoperatively.

\section{Clinical significance of study results}

The results of this study did not support the primary hypothesis that perioperative dexamethasone, administered in the schedule prescribed in this study, (uniformly) decreases postoperative pain following SDE insertion. Pain relief, nausea, and meningism scores, and drug (analgesic, antiemetic, antipyretic) requirements were also not significantly superior in the dexamethasone-treated group: only temperature and nausea relief scores were significantly different between the control and dexamethasone groups with the direction being in favour of dexamethasone. However, we did observe that dexamethasone administration was associated with lower pain, nausea, and meningism scores, higher pain relief scores, and less antipyretic and analgesic use compared to placebo.

The lack of observed statistical significance between the control and dexamethasone pain scores may have several explanations. One must first consider the possibility of an underpowered study. However, this is unlikely as sample size was calculated using $95 \%$ power rather than the traditional $80 \%$ value, and, as mentioned previously, this study could detect a difference as small as $2.5 \mathrm{~cm}$ VAS. Second is the possibility of placebo effect. The estimated marginal means of the pain scores in the control group ranged from a minimum of just under 2.0 to a maximum of almost 5.0 (Figure 3a) - substantially lower than the mean pain scores measured by Wiebe et al in a nonrandomized prospective pilot study (mean pain VAS score $=$ 6.87 , unpublished data, 1996). Thus the placebo effect may have reduced the magnitude of the difference between the control and dexamethasone groups.

Notwithstanding the above possibilities, a qualitative analysis of the plots of estimated marginal means over time provides the likely explanation for the observed lack of statistical significance: a significant interaction between treatment effect and time was identified for pain scores $(\mathrm{p}=0.04)$ (Table 2). The scores remained similar for the control and dexamethasone groups for the first day following surgery; thereafter they diverged for approximately 36 hours with the dexamethasone group scores being consistently lower than the control values, only to approximate each other again by the third postoperative day. Similar patterns were seen for pain relief, nausea, nausea relief, and temperature. This observation suggests that dexamethasone has a delayed onset of action and limited duration of benefit, presumably because the morbidity associated with SDE insertion is self-limited as evidenced by the control and dexamethasone scores for pain, pain relief, and nausea approximating each other by the third postoperative day. It is therefore reasonable to hypothesize that:

1) Dexamethasone should be administered sooner than it was in the present study (1-2 hours prior to surgery) to allow beneficial effects to be realized in the early $(<24$ hours) postoperative period. The data suggest it should be given approximately 16-24 hours prior to surgery.

2) The duration of dexamethasone therapy should be limited to two days following surgery.

Finally, the results of the regression analysis suggested an inverse relationship between age and pain scores (unstandardized regression coefficient $-0.098, \mathrm{p}=0.004$ ). This was somewhat surprising given that our anecdotal experience had suggested that younger patients tended to experience less pain following SDE insertion.

\section{Study strengths, validity, and limitations}

Study strengths include the placebo-controlled double blind design, uniformity of the patient population, success of randomization, completeness of follow-up, use of patient selfassessment outcome measures, and use of a single individual to assess and record the meningism scores. The study subjects were also a representative sample of patients with medically intractable epilepsy who were being considered for candidacy for surgical intervention at a tertiary care epilepsy unit. The exclusion criteria of this study dictated that patients with a chronic pain syndrome or with developmental delay or impaired IQ that prevented them from understanding the VAS scale were excluded. Otherwise we judged that the study results are applicable to all patients with medically intractable epilepsy who are assessed in tertiary-care referral units.

In retrospect, a more focused primary hypothesis would have allowed appropriate data analysis to be defined a priori, but at the onset of the study we did not anticipate the magnitude of the delay in onset of treatment effect or the interaction between treatment effects over time. Indeed, it is often impossible in practice to specify in advance interactions one would want to test and unexpected new findings are always a possibility. It is therefore recommended to look for treatment-covariate interactions but to report them skeptically as hypotheses to be investigated in future studies. ${ }^{38}$ Finally, a measure of overall patient satisfaction with their care and degree of comfort at the conclusion of the measurement period might have provided additional interesting data for analysis. Similarly, measuring nurses' assessments regarding patient comfort would also have been of interest, and possibly supportive of the study conclusions.

\section{Conclusions}

This randomized double blind placebo-controlled clinical trial demonstrated that perioperative dexamethasone administration in patients undergoing SDE insertion for medically intractable epilepsy is safe and significantly reduces postoperative temperature and improves nausea relief compared to placebo. A significant interaction between treatment effect over time means that one should interpret carefully any difference in the main treatment effect of dexamethasone on pain VAS scores. The graphical plots of both the primary and secondary outcome variables suggested that morbidity is reduced by dexamethasone, but not uniformly over the duration of the monitoring period. The beneficial effects of dexamethasone appear to be delayed in onset, and of limited duration. Thus, although it appears to have a beneficial role, dexamethasone administered according the protocol used in this study cannot be 
recommended at the present time as a means to reduce postoperative pain following SDE insertion. Further study is necessary to determine the ideal dosing schedule. Given that postoperative morbidity following SDE insertion was selflimited it appears unnecessary to continue dexamethasone beyond 48 hours postoperatively. Earlier administration may also be preferable considering the delay in onset of beneficial effect. Whether dexamethasone needs to be tapered or whether it can be stopped abruptly remains unanswered.

\section{ACKNOWLEDGEMENTS}

The authors thank Nancy Absolon for assistance in patient recruitment and data collection, Suzan Matijevic for statistical assistance, and the Epilepsy Unit nursing staff.

\section{REFERENCES}

1. Wyler AR. Chronic intracranial monitoring techniques. In: Wyler AR, Hermann BP, (Eds). The Surgical Management of Epilepsy. Stoneham, MA: Butterworth-Heinemann, 1994: 62-69.

2. Wyler AR. Focal cortical resections. In: Wyler AR, Hermann BP, (Eds). The Surgical Management of Epilepsy. Stoneham, MA: Butterworth-Heinemann, 1994: 129-138.

3. Carmel PW, Fraser RAR, Stein BM. Aseptic meningitis following posterior fossa surgery in children. J Neurosurg 1974; 41: 44-48.

4. Foulkes GD, Robinson JS Jr. Intraoperative dexamethasone irrigation in lumbar microdiscectomy. Clin Orthop 1990: 224228.

5. King JS. Dexamethasone - a helpful adjunct in management after lumbar discectomy. Neurosurgery 1984; 14(6): 697-700.

6. Glasser RS, Knego RS, Delashaw JB, Fessler RG. The perioperative use of corticosteroids and bupivacaine in the management of lumbar disc disease. J Neurosurg 1993; 78: 383-387.

7. Layne MH, Bilsky MH. Epidural steroids, postoperative morbidity, and recovery in patients undergoing microsurgical lumbar discectomy. J Neurosurg 1992; 77: 90-95.

8. Henzi I, Walder B, Tramer MR. Dexamethasone for the prevention of postoperative nausea and vomiting. Anesth Analg 2000; 90: 186-194.

9. Guyatt GH, Berman LB, Townsend M, Taylor DW. Should study subjects see their previous response? J Chronic Dis 1985; 38(12): 1003-1007.

10. Price DD, McGrath PA, Rafii A, Buckingham B. The validation of visual analogue scales as ratio scale measures for chronic and experimental pain. Pain 1983; 17: 45-56.

11. Melzack R, Katz J. Pain measurement in persons in pain. In: Wall PD, Melzack R, (Eds). Textbook of Pain. 3rd ed. New York 1994: Churchill Livingstone: 337-351 .

12. Huskisson EC. Measurement of pain. Lancet 1974; 2: 1127-1131.

13. McQuay HJ, Moore A. Pain measurement, study design, and validity. In: McQuay HJ, Moore A, (Eds). An evidence-based resource for pain relief. Oxford: Oxford University Press 1998: 14-18.

14. Huskisson EC, Wojtulewski JA, Berry H, et al. Treatment of rheumatoid arthritis with fenoprofen: comparison with aspirin. $\mathrm{Br}$ Med J 1974; 1(900): 176-180.

15. Mattson RH, Cramer JA, Collins JF, et al. Comparison of carbamazepine, phenobarbital, phenytoin, and primidone in partial and secondary generalized tonic-clonic seizures. N Engl J Med 1985; 313: 145-151

16. Wiebe S, Blume WT, Girvin JP, Eliasziw M. A randomized, controlled trial of surgery for temporal-lobe epilepsy. N Engl J Med 2001; 345: 311-318
17. Spencer SS, Sperling MR, Shewmon DA. Intracranial electrodes. In: Engel J Jr., Pedley TA, (Eds). Epilepsy. A Comprehensive Textbook. Philadelphia:Lippincott-Raven 1997: 1719-1747.

18. Espinosa J, Olivier A, Andermann F, et al. Morbidity of chronic recording with intracranial depth electrodes in 170 patients. Stereotact Funct Neurosurg 1995; 63: 63-65.

19. Ross DA, Henry TR. Morbidity associated with subdural electrodes (letter; comment). J Neurosurg 1991; 75:832.

20. Seigel AM, Roberts DW, Thadani VM, et al. The role of intracranial electrode reevaluation in epilepsy patients after failed initial invasive monitoring. Epilepsia 2000; 41: 571-580.

21. Van Veelen CW, Debets RM. Functional neurosurgery in the treatment of epilepsy in the Netherlands. Aspects of presurgical evaluation and the contribution of subdural and stereotactically implanted depth electrodes in the Dutch Workgroup for Functional Surgery. Acta Neurochir (Wien) 1993; 124: 7-10.

22. Wiggins GC, Elisevich K, Smith BJ. Morbidity and infection in combined subdural grid and strip electrode investigation for intractable epilepsy. Epilepsy Res 1999; 37: 73-80.

23. Wyler AR, Walker G, Somes G. The morbidity of long-term seizure monitoring using subdural strip electrodes. J Neurosurg 1991; 74: 734-737.

24. Behrens E, Zentner J, van Roost D, et al. Subdural and depth electrodes in the presurgical evaluation of epilepsy. Acta Neurochir (Wien) 1994; 128: 84-87.

25. Penfield W, Jasper H. Epilepsy and the functional anatomy of the human brain. Boston: Little, Brown, 1954.

26. Bloomstedt GC. Postoperative aseptic meningitis. Acta Neurochir (Wien) 1987; 89: 3-4.

27. Hammes EM Jr. Reaction of the meninges to blood. Arch Neurol Psychiatry 1944; 52: 505-514.

28. Mathiesen T, Fuchs D, et al. Increased CSF neopterin levels in subarachnoid hemorrhage. J Neurosurg 1990; 73(1): 69-71.

29. Oestergaard JR, Kristensen BO, Svehag S, et al. Immune complexes and complement activation following rupture of intracranial saccular aneurysms. J Neurosurg 1987; 66: 891-897.

30. Pelletieri L, Nilsson B, et al. Serum immunocomplexes in patients with subarachnoid hemorrhage. Neurosurgery 1986; 19: 767.

31. Schimmer BP, Parker KL. ACTH: adrenocortical steroids and their synthetic analogs. In: Hardman JG, Limbird LH, Molinoff PB, Ruddan RW, Goodman Gilman A, (Eds). Goodman \& Gilman's The Pharmacologic Basis of Therapeutics (9th ed). New York: McGraw Hill 1985: 1459-1486.

32. Wang JJ, Ho ST, Liu YH, et al. Dexamethasone reduces nausea and vomiting after laparoscopic cholecystectomy. Br J Anaesth 1999; 83: 772-775

33. Wang JJ, Ho ST, Tzeng JI, Tang CS. The effect of timing of dexamethasone administration on its efficacy as a prophylactic antiemetic for postoperative nausea and vomiting. Anesth Analg 2000; 91: 136-139.

34. Waagner DC, Kennedy WA, Hoyt MJ. Lack of adverse effects of dexamethasone therapy in aseptic meningitis. Ped Inf Dis J 1990; 12: 922-923.

35. Liu K, Hsu CC, Chia YY. Effect of dexamethasone on postoperative emesis and pain. Br J Anaes 1998; 80: 85-86.

36. Pappas ALS, Sukhani R, Hotaling AJ, et al. The effects of preoperative dexamethasone on the immediate and delayed postoperative morbidity in children undergoing adenotonsillectomy. Anesth Analg 1998; 87: 57-61.

37. Wang JJ, Ho ST, Liu HS, Ho CM. Prophylactic antiemetic effect of dexamethasone in women undergoing ambulatory laparoscopic surgery. Br J Anaesth 2000; 84 (4): 459-462.

38. Freidman LM, Furberg CD, DeMets DL. Issues in data analysis. In: Friedman LM, Furberg CD, DeMets DL, (Eds). Fundamentals of Clinical Trials, 3rd ed. St Louis, Missouri, Mosby-Year Book Inc. 1996: 284-322. 